nonresponders vs untreated, $P=.084)$. This is despite the fact that the rate of cirrhosis at the time of starting therapy was similar among the IFN-treated and untreated patients ( $46 \%$ vs $43 \%, P=.49$ ). The role of IFN therapy as a time-varying covariant in our cohort has limited value due to the retrospective analysis of our study. For this reason, as well as the relatively small number of subjects in every group, we agree that the results should be viewed with caution.

Finally, the baseline-event-anticipation score ${ }^{6}$ that can assess the risk of developing clinical events is helpful in daily clinical practice. However, its validation in other cohorts such as African subjects and the inclusion of other factors like the presence of detectable HDV-RNA and/or quantitative HDV-RNA levels may increase the performance of this score.

Currently new drugs for chronic hepatitis delta are in the pipeline and, indeed, more efficient therapies will increase diagnosis and improve the management of these patients.

\section{ACKNOWLEDGEMENT}

The authors' declarations of personal and financial interests are unchanged from those in the original article. ${ }^{2}$

\section{LINKED CONTENT}

This article is linked to Palom et al and Sonneveld and de Knegt papers. To view these articles, visit https://doi.org/10.1111/apt.15521 and https://doi.org/10.1111/apt.15549.

Adriana Palom ${ }^{1}$ Mar Riveiro-Barciela ${ }^{1,2}$ iD
Maria Buti ${ }^{1,2}$ (iD) on behalf of all authors

${ }^{1}$ Liver Unit, Department of Internal Medicine, Hospital Universitari Vall d'Hebron, Universitat Autònoma de Barcelona, Barcelona, Spain

${ }^{2}$ Centro de Investigación Biomédica en Red de Enfermedades Hepáticas y Digestivas (CIBERehd), Barcelona, Spain Email:mar.riveiro@gmail.com

ORCID

Mar Riveiro-Barciela iD https://orcid.org/0000-0001-9309-2052

Maria Buti iD https://orcid.org/0000-0002-0732-3078

\section{REFERENCES}

1. Sonneveld MJ, de Knegt RH. Editorial: rapid disease progression in hepatitis delta-can we turn the tide? Aliment Pharmacol Ther. 2020; 51:172-173

2. Palom A, Rodríguez-Tajes $S$, Navascués $C A$, et al. Long-term clinical outcomes in patients with chronic hepatitis delta: the role of persistent viraemia. Aliment Pharmacol Ther. 2020;51:158-166.

3. Lampertico P, Agarwal K, Berg T, et al. EASL 2017 Clinical Practice Guidelines on the management of hepatitis B virus infection. J Hepatol. 2017;67:370-398.

4. Béguelin C, Moradpour D, Sahli R, et al. Hepatitis delta-associated mortality in HIV/HBV-coinfected patients. J Hepatol. 2017;66:297-303.

5. Wranke A, Serrano BC, Heidrich B, et al. Antiviral treatment and liverrelated complications in hepatitis delta. Hepatology. 2017;65:414-425.

6. Calle Serrano B, Großhennig A, Homs M, et al. Development and evaluation of a baseline-event-anticipation score for hepatitis delta. J Viral Hepatitis. 2014;21:e154-163.

\title{
Editorial: moving towards the appropriate use of proton pump inhibitors
}

Proton pump inhibitors (PPIs) are distinct from nearly any other medication class by virtue of their wide range of indications. They have legitimate uses for both intermittent symptoms (e.g., gastro-oesophageal reflux disease [GERD]) and for the prevention of a life-threating condition (e.g., gastrointestinal bleeding). In this respect, only aspirin might be comparable. Nevertheless, in the minds of both patients and clinicians, PPIs tend to be associated overwhelmingly with GERD. In clinical practice and research, adequate attention to PPI indication will be the key to future efforts to reduce appropriate use.
Ghosh et al explored how patients and physicians, both in general and specialty medical clinics, perceived the harms associated with PPIs, and whether either group had changed their use of these drugs. ${ }^{1}$ They found that nearly half of patients reported knowledge of PPI adverse effects, and that $38 \%$ had changed their PPI use as a result. Furthermore, $60 \%$ of physicians had familiarity with PPI adverse effects, and $37 \%$ had changed their practice. These findings are in general agreement with other surveys on this topic, ${ }^{2,3}$ and highlight that concerns about adverse effects have drawn the attention 
of both parties. However, PPI indication was not a topic of either survey.

With a constantly growing number of observational studies demonstrating associations of PPIs with multiple adverse effects, it can be easy to lose sight of the potential life-saving benefits of PPIs. Notwithstanding the results of a recent study among patients on low-dose rivaroxaban and/or aspirin, ${ }^{4}$ in a meta-analysis of randomised controlled trials, PPIs reduced the risk of bleeding peptic ulcers by nearly $80 \%{ }^{5}$ They may be especially beneficial to older patients, who are at greater risk for peptic ulcer disease and its sequelae. ${ }^{6}$ It also increasingly appears that PPIs have a vital role in the treatment of Barrett's oesophagus. In the AspECT trial, a randomised factorial trial of esomeprazole and aspirin for patients with Barrett's oesophagus, high-dose PPI compared with low-dose PPI was associated with a delay in the composite outcome of all-cause mortality, oesophageal adenocarcinoma, or high-grade dysplasia. ${ }^{7}$ While the clinical upshot of these studies continues to be debated, they underscore that PPIs have a crucial role in the treatment of patients with conditions perpetuated by gastric acid.

Our goal should be to get the right patients on PPIs, and it is safe to say that we have much room for improvement. While PPIs have been overused for GERD or in patients without any indication at all, ${ }^{8}$ they have also long been underused for the prevention of peptic ulcer disease. ${ }^{9}$ Without due attention to PPI indications, risks and benefits, efforts by patients and physicians to stop the drugs could cause unintended harm. ${ }^{10}$ Given a now abundant body of evidence on PPI use, it is time to move on to the development of clinically nuanced interventions to help clinicians (and their patients) make the right choices about PPIs.

\section{ACKNOWLEDGEMENTS}

Declaration of personal interests: None.

\section{FUNDING INFORMATION}

This project was supported by NIDDK K23 118179-01A1 (JEK) and $\mathrm{NCl}$ U01CA199336 and U54CA163059 (JHR). The funding source had no role in drafting of the manuscript. The contents do not represent the views of the US Department of Veterans Affairs or the US Government.

\section{LINKED CONTENT}

This article is linked to Ghosh et al and Schnoll-Sussman and Katz papers. To view these articles, visit https://doi.org/10.1111/apt.15522 and https://doi.org/10.1111/apt.15591.

$$
\text { Jacob E. Kurlander }{ }^{1,2,3}
$$

Joel H. Rubenstein ${ }^{1,2,3,4}$ (iD

${ }^{1}$ Veterans Affairs Ann Arbor Healthcare System, Ann Arbor, MI, USA

${ }^{2}$ Department of Internal Medicine, University of Michigan, Ann Arbor, MI, USA

${ }^{3}$ Institute for Healthcare Policy and Innovation, University of Michigan, Ann Arbor, MI, USA

${ }^{4}$ Veterans Affairs Ann Arbor Center for Clinical Management Research, Ann Arbor, MI, USA

Email:jkurland@umich.edu

\section{ORCID}

Jacob E. Kurlander (iD https://orcid.org/0000-0003-1798-060X

Joel H. Rubenstein (D) https://orcid.org/0000-0001-7189-3254

\section{REFERENCES}

1. Ghosh G, Schnoll-Sussman F, Mathews S, Katz PO. Reported proton pump inhibitor side effects: what are physician and patient perspectives and behaviour patterns? Aliment Pharmacol Ther. 2020;51:121-128.

2. Kurlander JE, Kolbe M, Scheiman JM, et al. The right idea for the wrong patient: results of a national survey on stopping PPIs. Clin Gastroenterol Hepatol. 2017;15:1475-1476.

3. Kurlander JE, Kennedy JK, Rubenstein JH, et al. Patients' perceptions of proton pump inhibitor risks and attempts at discontinuation: a national survey. Am J Gastroenterol. 2019;114:244-249.

4. Moayyedi P, Eikelboom JW, Bosch J, et al. Pantoprazole to prevents gastroduodenal events in patients receiving rivaroxaban and/ or aspirin in a randomized, double-blind, placebo-controlled trial. Gastroenterology. 2019;157:403-412.

5. Scally B, Emberson JR, Spata E, et al. Effects of gastroprotectant drugs for the prevention and treatment of peptic ulcer disease and its complications: a meta-analysis of randomised trials. Lancet Gastroenterol Hepatol. 2018;3:231-241.

6. Li L, Geraghty OC, Mehta Z, Rothwell PM; Oxford Vascular Study. Age-specific risks, severity, time course, and outcome of bleeding on long-term antiplatelet treatment after vascular events: a population-based cohort study. Lancet. 2017;390:490-499.

7. Jankowski J, de Caestecker J, Love SB, et al. Esomeprazole and aspirin in Barrett's oesophagus (AspECT): a randomised factorial trial. Lancet. 2018;392:400-408.

8. Heidelbaugh JJ, Goldberg KL, Inadomi JM. Magnitude and economic effect of overuse of antisecretory therapy in the ambulatory care setting. Am J Manag Care. 2010;16:e228-234.

9. MedlockS, EslamiS, AskariM, etal.Co-prescription of gastroprotective agents and their efficacy in elderly patients taking nonsteroidal anti-inflammatory drugs: a systematic review of observational studies. Clin Gastroenterol Hepatol. 2013;11:1259-1269.e10.

10. Platt KD, Saini SD, Kurlander JE. Selecting the appropriate patients for proton pump inhibitor discontinuation: a teachable moment. JAMA Intern Med. 2019;179. https://doi.org/10.1001/jamaintern med.2019.2382 